\section{Estimation of change in forest aboveground carbon in Bhimbandh Wildlife Sanctuary, Bihar, India between 2007 and 2016}

\author{
Suman Sinha* and Abhisek Santra \\ Department of Civil Engineering, Haldia Institute of Technology, \\ Hatiberia, Haldia 721657 , India
}

This study analyses the status and temporal dynamics of the tropical forest aboveground carbon (AGC) stocks. We used an integrated geospatial approach incorporating satellite synthetic aperture radar (SAR) data with a continuous forest inventory over a tenyear period utilizing statistical up-scaling procedure over a tropical deciduous forest of India as a case study. Logarithmic regression relationship was observed as the best fit model to derive the aboveground biomass from SAR backscatter coefficients with an absolute model accuracy of $\mathbf{8 0 . 6 1 \%}$. This was further employed to model the change in forest AGC stock from 2007 to 2016. Results show a significant decrease in carbon stock and the release of $918.5 \mathrm{Gg}$ of carbon in the atmosphere from deforestation and forest degradation in the study area within the ten-year period.

Keywords: Carbon, forest aboveground biomass, regression, synthetic aperture radar.

GLOBAL carbon dioxide $\left(\mathrm{CO}_{2}\right)$ concentration has surpassed the alarming level of $400 \mathrm{ppm}$ that would never relapse back in recent future ${ }^{1,2}$. Increase of atmospheric $\mathrm{CO}_{2}$ leads to global warming, ultimately resulting in abrupt climate transformations ${ }^{3}$, mainly owing to anthropogenic activities ${ }^{4}$. Forest is the most vital ecosystem component that regulates the carbon cycle by sequestering $\mathrm{CO}_{2}$ within terrestrial landscapes in its biomass ${ }^{5}$. Hence, the forest aboveground biomass (AGB) that monitors the terrestrial carbon balance serves as an important parameter measuring the forest aboveground carbon $(\mathrm{AGC})^{2}$. Temporal monitoring of forest carbon stocks provides information regarding REDD (reducing emissions from deforestation and forest degradation) ${ }^{5}$ and gives an insight into the forest health and global climate alteration phenomena ${ }^{6}$.

Remote sensing offers the best provision for continual monitoring and enumeration of forest carbon stocks, important for REDD/REDD+ monitoring ${ }^{7}$. Forest $\mathrm{CO}_{2}$ emissions can be empirically calculated from forest $\mathrm{AGB}^{2}$, which in turn can be measured through remote sensing ${ }^{8}$. The direct method for AGB estimation includes field inventory, while the indirect method uses remote sensing satellite sensors ${ }^{8,9}$. Both optical and radar data are extensively used for AGB studies, but active remote sensing

\footnotetext{
*For correspondence. (e-mail: sumanrumpa.sinha@gmail.com)
}

sensors, like the synthetic aperture radar (SAR) prove beneficial over the optical remote sensing ${ }^{10}$; however, the integrated use of optical sensors and SAR also proved valuable $^{11}$. Extensive use of SAR for biomass studies is well documented $^{8,10}$. It can be applied to enumerate the forest AGC concentration with significant accuracy ${ }^{12}$.

The limitations of optical sensors in biomass estimation are overcome by SAR due to its innate capabilities. SAR data are available in multi-polarized multifrequency bands, and shorter frequency bands like $\mathrm{L}$ and $\mathrm{P}$ with cross polarization are more useful for biomass studies due to greater penetration through canopy ${ }^{10,13}$. However, co-polarization, like $H H$ (horizontal-horizontal polarization) showed higher interactions with the vertical structured trunk and main stem than cross-polarization data, like $H V$ (horizontal-vertical polarization), revealing greater sensitivity towards the bole $\mathrm{AGB}^{2,11,14-17}$. A limitation of SAR in AGB estimation is the saturation of AGB estimates at a threshold level producing a logarithmic relation between AGB and SAR backscatter values $^{14,18,19}$. The AGB saturation levels for SAR bands are biome-specific and vary with biogeophysical characteristics of any ecosystem ${ }^{10,13,20-22}$. Uncertainties in the estimates are dependent on various factors like SAR frequency, reference data, forest stand structural attributes, species composition and complexities, etc. ${ }^{10,20,23}$.

The study uses the top-down-bottom-up approach integrating field inventory and geospatial technology for monitoring the decadal forest carbon stocks in context to REDD over a tropical deciduous forest area. Due to the limited accessibility of the study area, we had to depend mainly on remote sensing data for obtaining information.

Bhimbandh Wildlife Sanctuary is a tropical deciduous mixed forest in Munger, Bihar, India (25 $19^{\prime} 30^{\prime \prime}-$ $24^{\circ} 56^{\prime} 50^{\prime \prime} \mathrm{N}$ lat and $86^{\circ} 33^{\prime} 33^{\prime \prime}-86^{\circ} 11^{\prime} 51^{\prime \prime} \mathrm{E}$ long). Figure 1 study region covers an area of $672.65 \mathrm{~km}^{2}$ with approximately $89 \%$ under forest cover as of 2010 . Summer maximum temperature rises up $45^{\circ} \mathrm{C}$, winter minimum temperature ranges around $3.5^{\circ}-9^{\circ} \mathrm{C}$ and annual rainfall is $1078.7 \mathrm{~mm}$ on an average. The sanctuary has mainly sal forest, bamboo forest, scrub and many small forests with diverse species of flora. Significant flora comprise of Shorea robusta (sal), Diospyros melanoxylon (kendu), Boswellia serrata (salai), Terminalia tomentosa (asan), Madhuca longifolia (mahua), Acacia catechu (khair) and Dendrocalamus strictus (bamboo) ${ }^{24}$.

The top-down-bottom-up approach consists of two sections. First, the top-down section where the entire study area is reduced to a few representative samples on which the model for estimation is developed. Second, the bottom-up section where the model is applied over the entire area to generate estimates for the entire area, represented as spatial maps created in GIS framework.

SAR data from ALOS PALSAR of 2007 and ALOS-2 PALSAR-2 of 2016 with similar month of data acquisition were used in the study. Table 1 shows the specifications. 


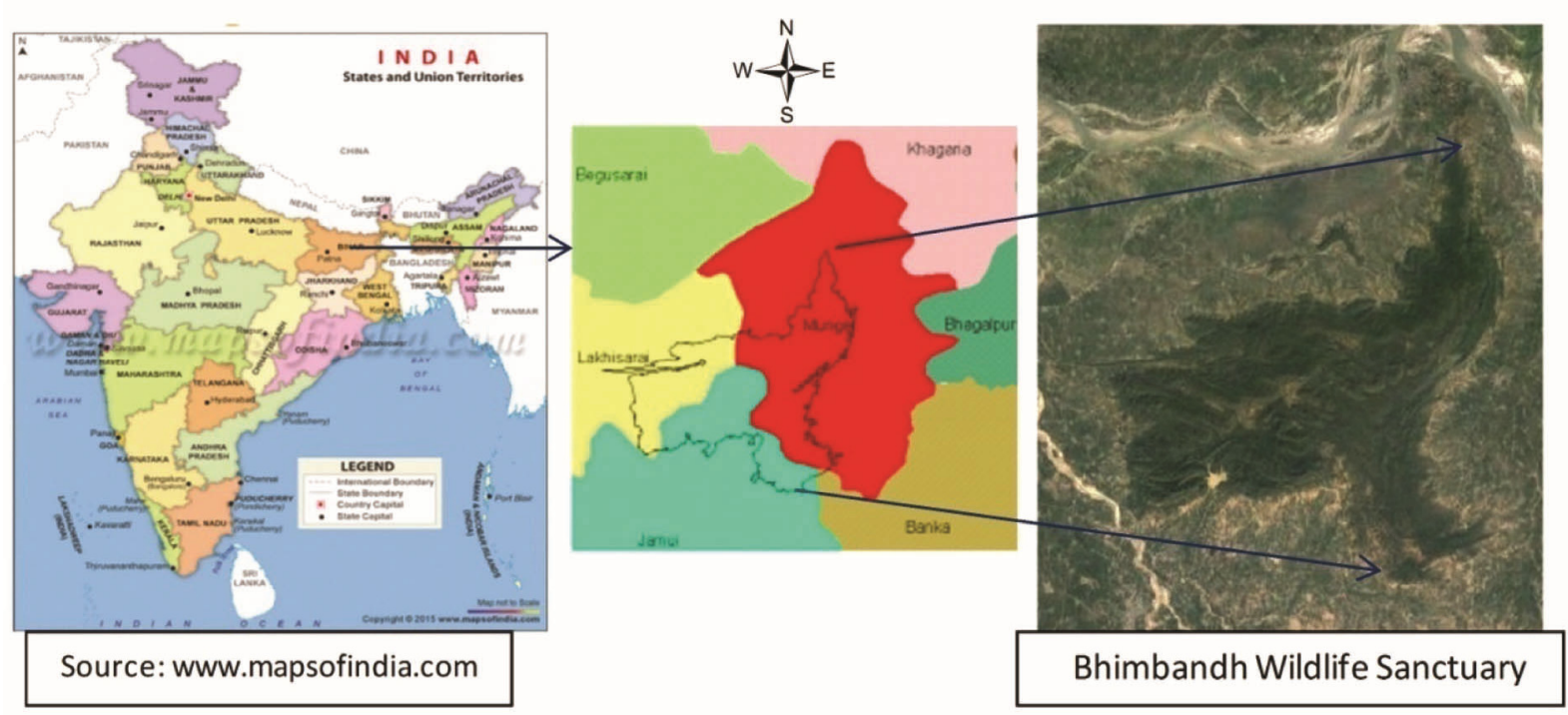

Figure 1. Maps showing the location of Bhimbandh Wildlife Sanctuary in Bihar, India.

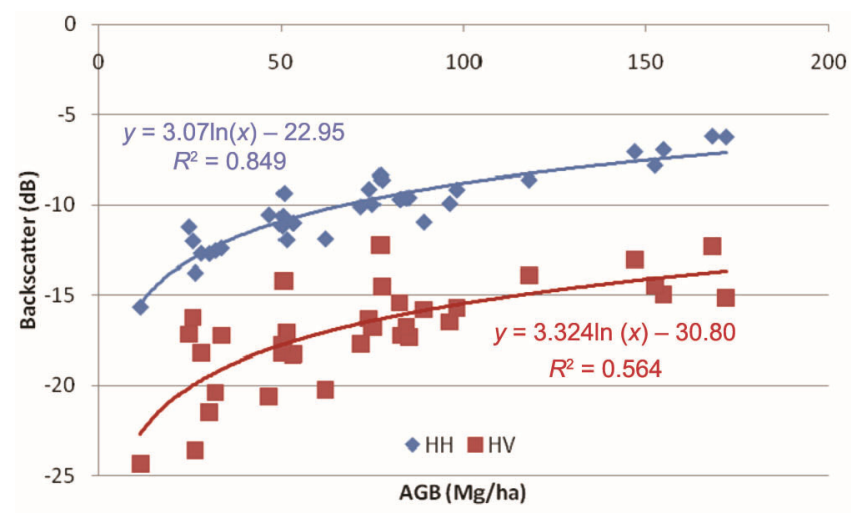

Figure 2. Relation between aboveground biomass (AGB) and synthetic aperture radar (SAR) backscatter values ( $H H$ : Horizontalhorizontal polarization, $H V$ : horizontal-vertical polarization).

Table 1. Specifications of synthetic aperture radar (SAR) data used

\begin{tabular}{lcc}
\hline Parameters & \multicolumn{2}{c}{ SAR data } \\
\hline Satellite & ALOS & ALOS-2 \\
Sensor/payload & PALSAR & PALSAR-2 \\
Launching country (organization) & Japan (JAXA) & Japan (JAXA) \\
Date of launch & 24 January 2006 & 24 May 2014 \\
Spatial resolution (m) & 25 & 3 \\
Swath width $(\mathrm{km})$ & 70 & 70 \\
Incident angle $\left({ }^{\circ}\right)$ & 34.3 & $35.3^{\circ}$ \\
Wavelengths/bands & L-band & L-band \\
Mode and polarization & Fine beam dual & Full (quad) pol \\
& $(H H / H V)$ & $(H H / H V / V H / V V)$ \\
Number of looks (azimuth : range) & $4: 1$ & $1: 1$ \\
Data acquisition year & 2007 & 2016 \\
Data source & \multicolumn{2}{c}{ JAXA (Japan) } \\
\hline
\end{tabular}

A total of 45 random square sample plots of $1000 \mathrm{~m}^{2}$ (0.1 ha) area were selected, of which $80 \%$ (i.e. 36 ) was used to design the AGB regression model and the rest $20 \%$ (i.e. 9) for model validation and confirming the pre- diction accuracy, according to the Pareto principle. A sample of 30 or more statistically represents the normal distribution of any sampling ${ }^{25}$, and the required sample size can vary between $0.001 \%$ and $0.005 \%$ of the total study area ${ }^{26}$. Tree-specific volumetric equations that incorporate tree height and girth information collected from the plot were used to derive the tree stem volume, which when multiplied with the respective specific gravity generated the tree $\mathrm{AGB}^{6}$. All the tree AGB values of a particular plot were summed to derive the field-based plot AGB of that particular sample plot.

The preprocessing of raw single look complex (SLC) ALOS PALSAR and ALOS-2 PALSAR-2 data was performed in a sequence of steps in SARScape and SNAP software respectively. Slant range distortions in SAR data were eliminated in the conversion of slant range image to ground range image, resulting in equal pixel-spaced SLC data. Square pixels in the imagery were produced by multilooking that simultaneously reduces the speckles occurring in the imagery. The data occurring in complex number format were converted to amplitude and power images in order to obtain floating-point image with real values in the pixels. The image was georectified using satellite orbital parameters and terrain-corrected using range Doppler approach with SRTM DEM resampled to $30 \mathrm{~m}$ pixel size by nearest neighbourhood algorithm and finally reprojected to the UTM-WGS84 coordinate system. Radiometric calibration was performed, converting the power data to linear backscatter and decibel image using eq. (1) below ${ }^{27}$.

$$
\sigma^{0}=10^{*} \log 10(\text { POWER })+\mathrm{CF}-A,
$$

where $\sigma^{0}$ is the backscatter value $(\mathrm{dB})$, POWER the power image, $\mathrm{CF}(=-83.0)$ the calibration factor and $A$ 


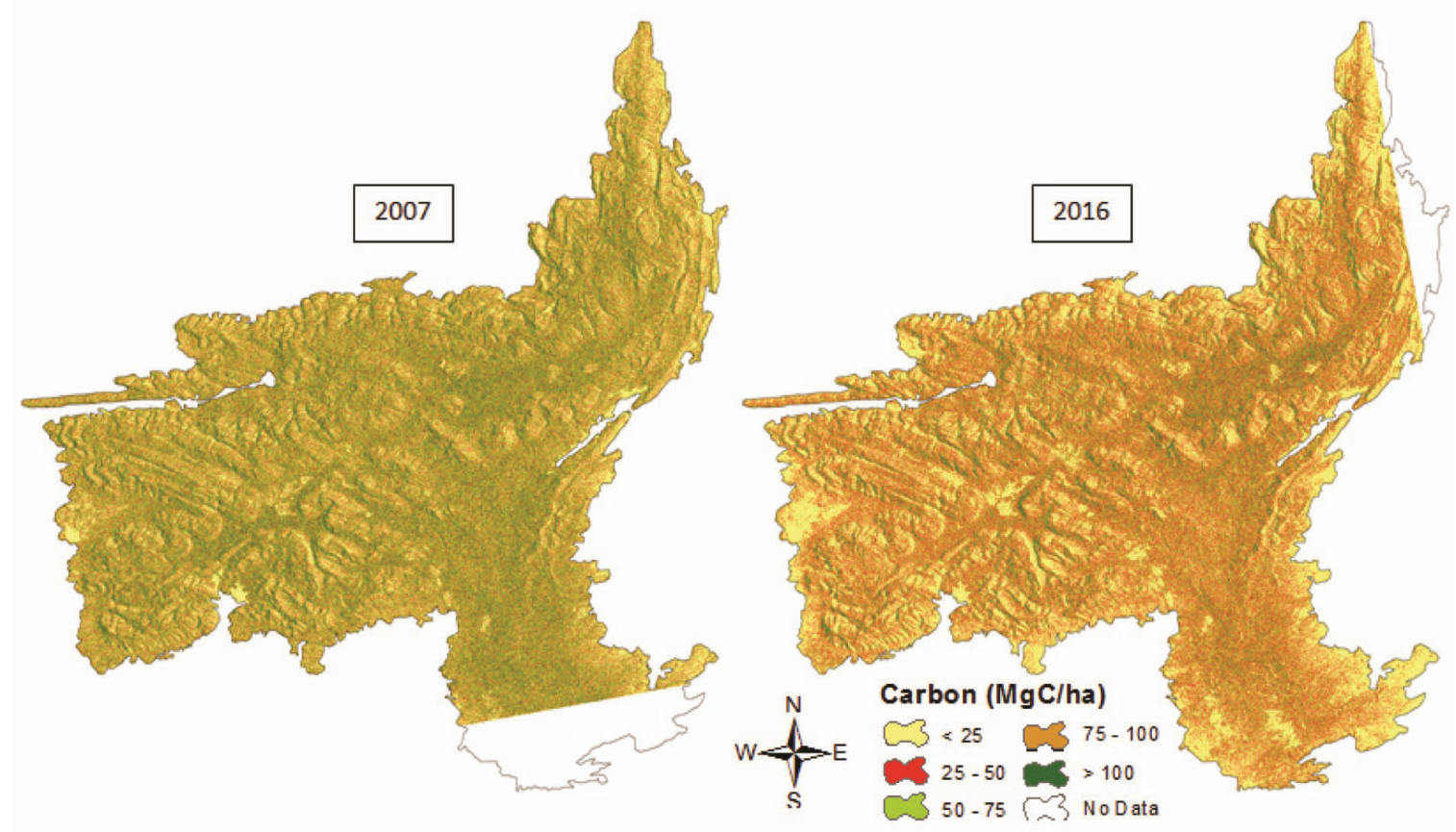

Figure 3. Estimated aboveground carbon (AGC) stocks in 2007 and 2016.

Table 2. Temporal carbon measurements for 2007 and 2016

\begin{tabular}{lrr}
\hline Parameters & 2007 & 2016 \\
\hline Mean aboveground biomass (AGB) $(\mathrm{Mg} / \mathrm{ha})$ & 78.88 & 51.57 \\
Total AGB $(\mathrm{Gg})$ & 5306.06 & 3469.06 \\
Mean carbon $(\mathrm{MgC} / \mathrm{ha})$ & 39.44 & 25.79 \\
SD of carbon $(\mathrm{MgC} / \mathrm{ha})$ & 163.91 & 106.33 \\
Total carbon $(\mathrm{GgC})$ & 2653.03 & 1734.53 \\
Equivalent $\mathrm{CO}_{2}(\mathrm{Gg})$ & 9736.63 & 6365.72 \\
\hline
\end{tabular}

$(=32.0)$ is the conversion factor for the level 1.1 SLC product.

The best-fit regression model was developed using the relationship between field-inventory AGB values based on randomly selected 36 sample plots with the corresponding SAR $\sigma^{0}$ values. The AGC model was derived from the AGB model using the carbon fraction value. Approximately, the carbon content as forest AGC is $50 \%$ of the forest $\mathrm{AGB}^{2,12,15}$ and the equivalent carbon dioxide emission is obtained by multiplying AGC with 3.67 (refs $5,12)$. The AGB model on which the AGC model is designed has been validated with the remaining $20 \%$ of the plot data using statistical metrices ${ }^{11}$. The spatio-temporal AGC maps were generated in a GIS framework to measure the decadal change in forest AGC content.

Landsat imagery of 2007 and 2016 was used to classify the study region into forest and non-forest areas to measure changes in the forest-cover using visual interpretation from the standard false colour composite (FCC) images. The overall decline in forest cover from 2007 to 2016 was $10.6 \mathrm{~km}^{2}$ (Table 2).
Field-inventorized minimum, maximum, mean and standard deviation values for AGB were 11.35, 172.07, 73.31 and 40.62 t/ha respectively. Figure 2 shows a logarithmic relation between $\mathrm{AGB}$ and SAR backscatter values, where $H V$ polarization shows relatively early saturation than $H H$ polarization. Also, Figure 2 depicts the relatively wide range of backscatter values in forests for $H V$ data $(-25$ to $-12 \mathrm{~dB})$ in comparison to narrower ranges for $H H$ data $(-15$ to $-6 \mathrm{~dB})$. However, $H H$ polarization image shows a better relationship with the AGB plot in comparison to $H V$-polarized image from the $\mathrm{L}$ band SAR data (Figure 2), as shown in eq. (2).

$$
\sigma_{\mathrm{L}_{-} \mathrm{HH}}^{0}=3.07 \ln (\mathrm{AGB})-22.957 \text {. }
$$

Validating the model with the $20 \%$ sample data resulted in an $R^{2}$ of $0.71(P<0.001)$, RMSE of $22.34 \mathrm{t} /$ ha and Willmott's index of agreement of 0.88 . This reveals that the model generates predicted values that fit the actual field values with high levels of agreement, and the absolute accuracy of the model is $80.6 \%$. The AGC model (eq. (3)) was derived as an inversion of the logarithmic relation in eq. (2) and considering the $50 \%$ contribution of carbon in AGB, as mentioned earlier.

$$
\mathrm{AGC}=0.5 \times \mathrm{AGB}=533.65 \times \mathrm{e}^{\left(0.2765 \times \sigma_{H H}^{0}\right)} .
$$

The AGC model in eq. (3) was used to develop the temporal AGC maps for 2007 and 2016, units expressed in $\mathrm{Mg} / \mathrm{ha}$. The maps have been reclassified into five groups 

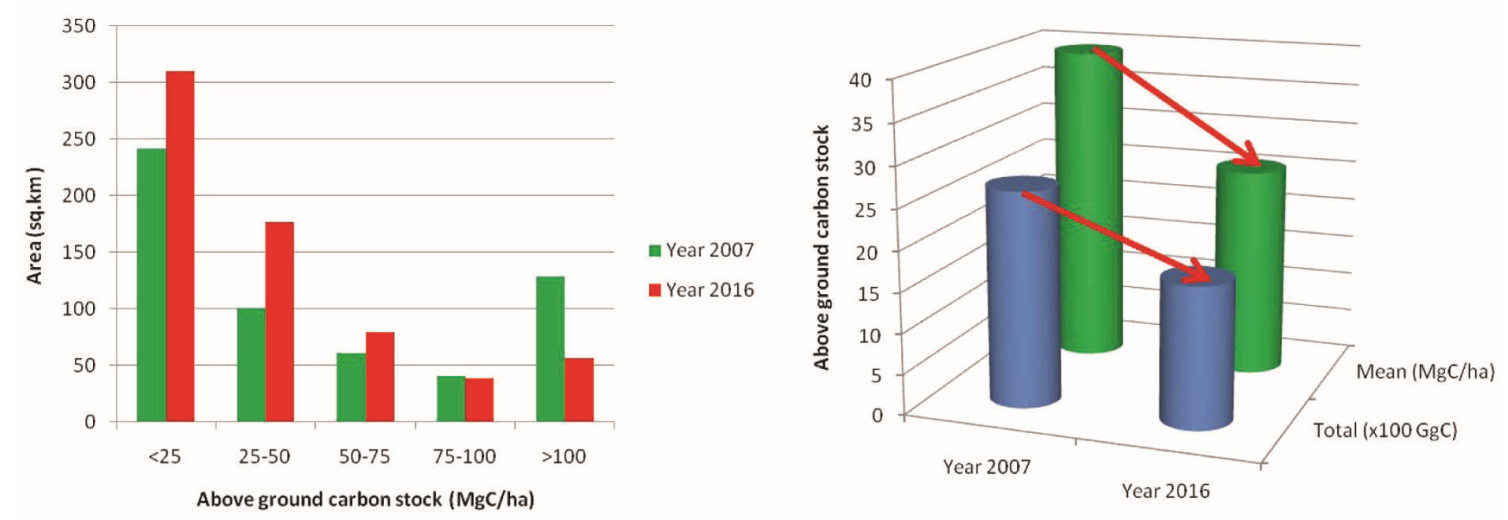

Figure 4. (Left) AGC stocks in 2007 and 2016. (Right) The total and mean AGC stocks for 2007 and 2016 are represented as blue and green cylinders respectively.

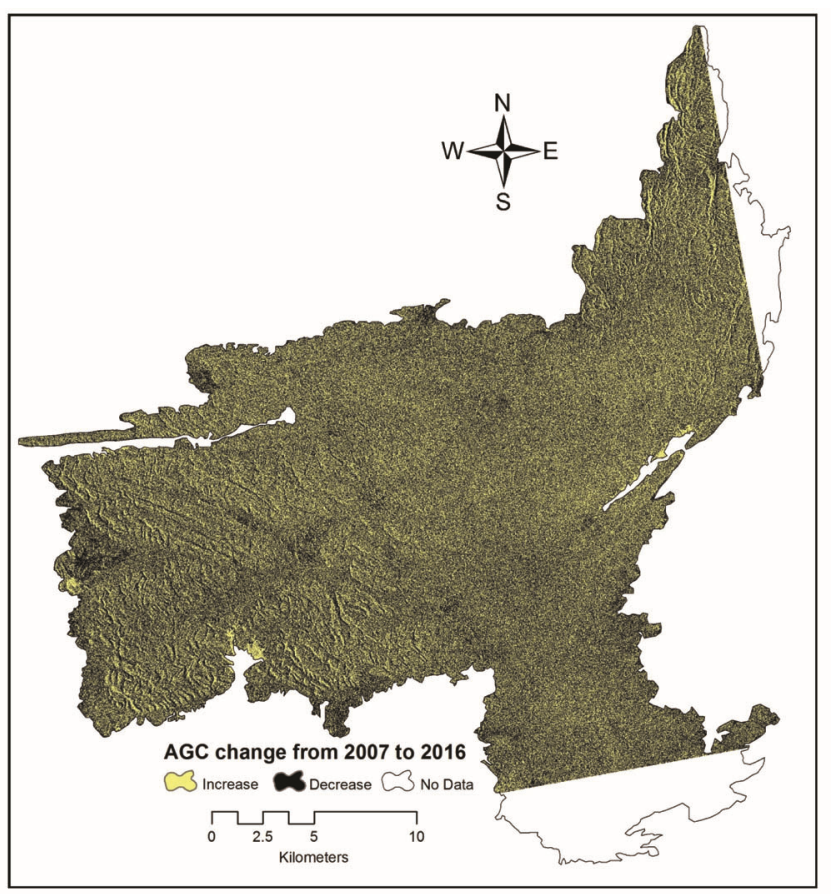

Figure 5. Temporal change in the forest carbon uptake.

(Figure 3). Carbon concentration less than $25 \mathrm{t} / \mathrm{ha}$ occurs near the periphery, settlements and water bodies, while concentration increases in the interior where vegetation density is high. Figure 3 signifies that forest AGC stock has decreased from 2007 to 2016; with most of the area within the $50 \mathrm{t} / \mathrm{ha}$ class during 2016 , while during 2007 , mostly the area showed concentration above $50 \mathrm{t} / \mathrm{ha}$ class. In 2007 , mean carbon concentration was $39.44 \mathrm{t} / \mathrm{ha}$ that decreased to $25.78 \mathrm{t} / \mathrm{ha}$ in 2016 (Table 2). Hence, the rate at which carbon stock decreased was $1.366 \mathrm{t} / \mathrm{ha} / \mathrm{yr}$ during the ten-year period. The total forest carbon stock was $26.5303 \times 10^{2} \mathrm{GgC}$ in 2007 that reduced to $17.3452 \times$ $10^{2} \mathrm{GgC}$ in 2016 (Table 2). The variance and standard deviation values also showed a decline during the period (Table 2). More the standard deviation or variance, more is the spread; hence, more spread was observed in 2007 than in 2016. Carbon concentration in the $>100 \mathrm{tC} / \mathrm{ha}$ class decreased considerably from 2007 to 2016, while for other classes the values increased, other than the 75$100 \mathrm{tC} /$ ha class showing a small decrease (Figure 4). As seen from Figure 4, the overall decline in forest carbon stock over the ten-year period was approximately $918.5 \mathrm{GgC}$. Figure 5 shows the pixel-wise spatial map of the change in the forest carbon uptake, with red colour depicting negative change, i.e. decrease in carbon stock from 2007 to 2016, and the green colour representing positive change or increase during the same temporal span.

Climate change and its impacts have severe consequences on the ecosystem, and human life and livelihood. Increase in atmospheric carbon concentration indicated by the ' $400 \mathrm{ppm}$ world' is the most dangerous crisis of the time. Most of the terrestrial biomass sequestered as forest aboveground bole biomass is indicative of carbon sequestered in the forest that can be measured and monitored using satellite data. Decrease of carbon sequestered within forests indicates that the carbon is set free in the atmosphere to contribute towards climate change leading to global warming. The same has been observed in the study area during the ten-year period, 2007-2016. Deforestation was not a major problem in the study site. Hence, the decline in carbon stock over the specified time period is mainly due to forest degradation.

Assessment of forest biomass through conventional in situ approach has several limitations in spite of having high accuracy levels. Remote sensing provides the only viable solution but has used uncertainties during assessment. However, continual monitoring of forest changes is possible with the huge archived data available. Hence remote sensing technology provides an easy, timely and cost-effective solution to the limitations of the in situ approach. Moreover, assessment using SAR data is even more advantageous than optical data, although there are certain limitations of the SAR-based approaches ${ }^{10}$. The successful wall-to-wall implementation of SAR 
remote sensing technology in forest carbon stock assessment has the potential to measure and monitor carbon stock changes in context to REDD/REDD+.

The present study aims to assess decadal carbon uptake variability over a tropical deciduous forest using remote sensing. A decrease of total and mean forest AGC stock was registered from $2.653 \times 10^{6} \mathrm{Mg}$ and $3944 \mathrm{Mg} / \mathrm{km}^{2}$ in 2007 to $1.734 \times 10^{6} \mathrm{Mg}$ and $2578 \mathrm{Mg} / \mathrm{km}^{2}$ in $2016 \mathrm{re}-$ spectively. This indicated a release of $918.5 \mathrm{Gg}$ of carbon to the atmosphere from deforestation and forest degradation in the study area during the ten-year time period. Forest degradation is the major factor for a decline in these estimates. The approach has significant applicability in computing and monitoring of forest AGC stocks in the scope of REDD/REDD+ and climate change scenario.

\section{Conflict of interest: None declared.}

1. Bala, G., Digesting 400 ppm for global mean $\mathrm{CO}_{2}$ concentration Curr. Sci., 2013, 104(11), 1471-1472.

2. Sinha, S. et al., Accounting tropical forest carbon stock with synergistic use of space-borne ALOS PALSAR and COSMO-Skymed SAR sensors. Trop. Ecol., 2019; doi:10.1007/s42965-019-00011-6.

3. Günlü, A. and Ercanlı, İ., Artificial neural network models by ALOS PALSAR data for aboveground stand carbon predictions of pure beech stands: a case study from northern of Turkey. Geocarto. Int., 2018; doi:10.1080/10106049.2018.1499817.

4. Ganeshamurthy, A. N., Ravindra, V., Rupa, T. R. and Bhat, P. M., Carbon sequestration potential of mango orchards in tropical hot and humid climate of Konkan region of India. Curr. Sci., 2019; https://www.currentscience.ac.in/cs/php/forthcoming/2019/29978. pdf (accessed on 18 March 2019).

5. Sharma, L. K., Nathawat, M. S. and Sinha, S., Top-down and bottom-up inventory approach for aboveground forest biomass and carbon monitoring in REDD framework using multi-resolution satellite data. Environ. Monit. Assess., 2013, 185(10), 8621-8637.

6. Kumar, P., Sharma, L. K., Pandey, P. C., Sinha, S. and Nathawat, M. S., Geospatial strategy for tropical forest-wildlife reserve biomass estimation. IEEE J. Sel. Top. Appl. Earth Obs. Remote Sensing, 2013, 6(2), 917-923.

7. De Sy, V., Herold, M., Archard, F., Asner, G. P., Held, A., Kellndorfer, J. and Verbesselt, J., Synergies of multiple remote sensing data sources for REDD+ monitoring. Curr. Opin. Environ. Sustain., 2012, 4(6), 696-706.

8. Lu, D., Chen, Q., Wang, G., Liu, L., Li, G. and Moran, E., A survey of remote sensing-based aboveground biomass estimation methods in forest ecosystems. Int. J. Digit. Earth, 2016, 9(1), 63-105.

9. Lu, D., The potential and challenge of remote sensing-based biomass estimation. Int. J. Remote Sensing, 2006, 27(7), 1297-1328.

10. Sinha, S., Jeganathan, C., Sharma, L. K. and Nathawat, M. S., A review of radar remote sensing for biomass estimation. Int. J. Environ. Sci. Technol., 2015, 12(5), 1779-1792.

11. Sinha, S., Jeganathan, C., Sharma, L. K., Nathawat, M. S., Das, A. K. and Mohan, S., Developing synergy regression models with space-borne ALOS PALSAR and Landsat TM sensors for retrieving tropical forest biomass. J. Earth Syst. Sci., 2016, 125(4), 725-735.

12. Sinha, S. et al., Regression-based integrated bi-sensor SAR data model to estimate forest carbon stock. J. Indian Soc. Remote Sensing, 2019; doi:10.1007/s12524-019-01004-7.

13. Pandey, U., Kushwaha, S. P. S., Kachhwaha, T. S., Kunwar, P. and Dadhwal, V. K., Potential of Envisat ASAR data for woody biomass assessment. Trop. Ecol., 2010, 51(1), 117-124.
14. Sinha, S., Santra, A., Sharma, L. K., Jeganathan, C., Nathawat, M. S., Das, A. K. and Mohan, S., Multi-polarized Radarsat-2 satellite sensor in assessing forest vigor from above ground biomass. J. For. Res., 2018, 29(4), 1139-1145.

15. Omar, H., Misman, M. A. and Kassim, A. R., Synergetic of PALSAR-2 and Sentinel-1A SAR polarimetry for retrieving aboveground biomass in Dipterocarp forest of Malaysia. Appl. Sci., 2017, 7(7), 675.

16. Sinha, S. et al., Multi-frequency SAR capabilities for forest biomass and carbon inventory for REDD monitoring. In Proceedings of the 38th Asian Conference on Remote Sensing (ACRS-2017), 23-27 October 2017, New Delhi, Asian Association on Remote Sensing; https://a-a-r-s.org/proceeding/ACRS2017/ID 753 1652/ 967.pdf

17. Torbick, N., Ledoux, L., Salas, W. and Zhao, M., Regional mapping of plantation extent using multisensory imagery. Remote Sensing, 2016, 8(3), 236.

18. Rahman, M. M. and Sumantyo, J. T. S., Retrieval of tropical forest biomass information from ALOS PALSAR data. Geocarto Int., 2012, 28(5), 382-403.

19. Askne, J. I. H., Soja, M. J. and Ulander, L. M. H., Biomass estimation in a boreal forest from TanDEM-X data, lidar DTM, and the interferometric water cloud model. Remote Sensing Environ., 2017, 196, 265-278.

20. Englhart, S., Keuck, V. and Siegert, F., Aboveground biomass retrieval in tropical forests - The potential of combined X- and Lband SAR data use. Remote Sensing Environ., 2011, 115(5), 1260-1271.

21. Ghasemi, N., Sahebi, M. R. and Mohammadzadeh, A., A review on biomass estimation methods using synthetic aperture radar data. Int. J. Geomat. Geosci., 2011, 1(4), 776-788.

22. Nizalapur, V., Jha, C. S. and Madugundu, R., Estimation of above ground biomass in Indian tropical forested area using multifrequency DLR-ESAR data. Int. J. Geomat. Geosci., 2010, 1(2), $167-178$.

23. Montesano, P. M. et al., The uncertainty of biomass estimates from LiDAR and SAR across a boreal forest structure gradient. Remote Sensing Environ., 2014, 154, 398-407.

24. Sinha, S., Sharma, L. K. and Nathawat, M. S., Integrated geospatial techniques for land-use/land-cover and forest mapping of deciduous Munger forests (India). Univ. J. Environ. Res. Technol., 2013, 3(2), 190-198.

25. Singh, I. J., Mizanurahman, M. and Kushwaha, S. P. S., Assessment of effect of settlements on growing stock in Thano range of Dehradun forest division using RS \& GIS. J. Indian Soc. Remote Sensing, 2006, 34(2), 209-217.

26. Kale, M. P., Ravan, S. A., Roy, P. S. and Singh, S., Patterns of carbon sequestration in forests of Western Ghats and study of applicability of remote sensing in generating carbon credits through afforestation/reforestation. J. Indian Soc. Remote Sensing, 2009, 37(3), 457-471.

27. Shimada, M., Isoguchi, O., Tadono, T. and Isono, K., PALSAR radiometric and geometric calibration. IEEE Trans. Geosci. Remote Sensing, 2009, 47(12), 3915-3932.

ACKNOWLEDGEMENTS. We thank the Space Applications Centre (ISRO), India and JAXA, Japan for providing SAR data. We also thank the Science and Engineering Research Board (SERB), Department of Science and Technology, Government of India for providing funds under SERB National Post-Doctoral fellowship scheme (File Number: PDF/2015/000043/EAS).

Received 30 May 2019; accepted 22 June 2019

doi: $10.18520 / \mathrm{cs} / \mathrm{v} 117 / \mathrm{i} 6 / 1090-1094$ 